\title{
Evaluation of interfacial sulfate complexation by a bis-thiourea ionophore at water- organic interfaces using microelectrochemistry and high resolution mass spectrometry
}

\author{
Eva Alvarez de Eulate, ${ }^{a, c}$ Francesco Busettib,c and Damien W. M. Arrigan*, a,c
}

${ }^{a}$ Nanochemistry Research Institute, ${ }^{b}$ Curtin Water Quality Research Centre, and 'Department of Chemistry, Curtin University, GPO Box U1987, Perth, Western Australia, 6845, Australia

* Author for correspondence. Email d.arrigan@curtin.edu.au, telephone +61-8-9266-9735

\begin{abstract}
Simple, fast and low cost methods for the detection of sulfate are required for different applications. Electrochemistry at water/o-nitrophenyloctylether (W/NPOE) interfaces was employed to evaluate sulfate detection by ionophore-facilitated ion-transfer at an array of micro-interfaces. With ionophore 1,3-[Bis(3-phenylthioureidomethyl)]benzene present in the NPOE phase, the transfer of sulfate across the interface was determined by voltammetry at ca. $-0.35 \mathrm{~V}$ for $0.01 \mathrm{M} \mathrm{Na}_{2} \mathrm{SO}_{4}$ on the Galvani potential scale. The potentiometric detection limit for sulfate was $0.6 \times 10^{-6} \mathrm{M}$, based on the shift in the half-wave transfer potential with concentration. Amperometric detection limits for forward and reverse ion transfer currents were determined to be $14 \times 10^{-6} \mathrm{M}$ and $0.8 \times 10^{-6} \mathrm{M}$, respectively. Electrochemical analysis of the halfwave potential versus $\log _{\mathbf{S O}_{4}^{2-}}^{\mathbf{w}}$ and the corresponding electrospray ionisation - high resolution mass spectrometry (ESI-HRMS) analysis of W/NPOE emulsions indicated interfacial complexation via the formation of 1:1 sulfate:ionophore complexes. ESI-HRMS analysis of W/NPOE emulsions formed with water samples from an advanced water treatment plant revealed the binding of the ionophore to potential interferences from this environment, thus providing a guide to sensor development.
\end{abstract}

Keywords: sulfate; ionophore; liquid-liquid interface; voltammetry; mass spectrometry;

\section{INTRODUCTION}

The design of ionophores for anion recognition via 'host-guest' interactions is an expanding field of research in inorganic and supramolecular chemistry [1] driven by the ubiquitous role of anions in various chemical and biological processes. The main disadvantage for anion recognition compared with cation recognition is that anions are larger, can vary in geometry, and can be sensitive to changes in $\mathrm{pH}$ [2]. For example, ionophores for sulfate are of interest as this double negatively charged oxoanion is challenging to extract from water due to its large hydration energy. The ability to monitor and detect sulfate is of relevance in water and soil pollution, particularly in the mining [3] and nuclear waste remediation [4] sectors. Nevertheless, biomedical applications are also important, as high levels of sulfate in urine can indicate renal failure [5].

The widely-used method for the determination of sulfate in aqueous samples is ion chromatography (IC),

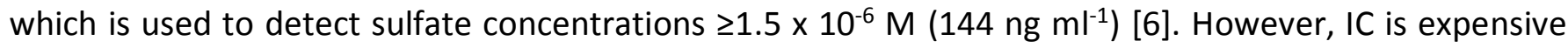
and time consuming, which consequently drives interest towards lower-cost methods such as sulfate sensors. Recent sensor studies have focused on colorimetry [7] and fluorimetry [8,9], in some cases coupled to catalytic reactions (e.g., with cysteine-modified gold nanoparticles) [10]. Similarly, polystyrene 
microspheres have been used to support ionophores for optical measurements in the presence of $\mathrm{pH}$ sensitive chromoionophores [11].

Traditionally, ion selective electrode (ISE) sensors have been an attractive alternative to optical/spectroscopic methods because of their lower cost and versatility to accommodate ionophores for either anions or cations. ISEs consist of an ionophore and an organic electrolyte in a polymeric membrane (usually polyvinyl chloride) prepared with a plasticizer (organic solvent).The ionophore can interact selectively with the analyte of interest, while the response is measured as the electromotive force (EMF) relative to the activity of the ion of interest. A variety of ionophores have been designed for sulfate recognition in ISE membranes, e.g. based on guanidinium [12], ferroceneamide [13], polyazacycloalkane [14], tris-urea [15], bis-thiourea $[16,17]$, and squaramide $[18,19]$ recognition groups. The main feature of these materials is the multiple $(\geq 2)$ binding sites available to interact with sulfate via $\mathrm{H}$-bonding. Amongst these publications, the limits of detection (LOD) reported are in the micromolar $\left(10^{-6} \mathrm{M}\right)$ range. For example, in a potentiometric sensor the bis-thiourea ionophore $\mathrm{N}$-[4-[4-[(anilinocarbothioyl) amino]benzyl]phenyl]-N-phenylthiourea gave a LOD of $0.2 \times 10^{-6} \mathrm{M}\left(19 \mathrm{ng} \mathrm{ml}^{-1}\right)$ [16], but selectivity over other anions was an issue. Receptors based on a tripodal squaramide structure presented a reasonable LOD $\left(1 \times 10^{-6} \mathrm{M} ; 96 \mathrm{ng} \mathrm{ml}^{-1}\right)$ with the advantage of improved affinity towards sulfate over chloride (logarithm of selectivity coefficient: -3.4) [18].

There have been few investigations of anion detection by dynamic electrochemistry at the interface formed between two immiscible electrolyte solutions (ITIES). Ion transfer (IT) and facilitated ion transfer (FIT) processes can be implemented at the ITIES via the imposition of a potential difference across the interface. FIT is achieved by using a receptor in one of the phases in a similar manner to ISEs. For instance, Shao's group [20] employed a calix-pyrrole ligand at water/dichloroethane microinterfaces to assist the transfer of monovalent anions. FIT of halides using cholapod receptors was investigated by Dryfe's group [21], while calixarenes and bis-thiourea moieties were used for phosphate [22,23] and sulfate [24] recognition at the ITIES. More recently, Chen's group [25] reported the use of an anion exchange membrane placed at the ITIES which resulted in an enlargement of the potential window and allowed the selective separation of various anions $\left(\mathrm{SO}_{4}{ }^{2-}, \mathrm{NO}_{3}{ }^{-}, \mathrm{ClO}_{4}{ }^{-}\right.$and $\left.\mathrm{Cl}^{-}\right)$without the need for a ligand in the organic phase.

The aim of the work presented here was to characterise the complexation of sulfate at a water/onitrophenyloctylether (W/NPOE) interface by a commercially-available ionophore using a combination of electrochemistry at a micro-ITIES array and electrospray ionisation - high resolution mass spectrometry (ESI-HRMS). In this way, information about the analytical sensitivity as well as the complexation of potential interferences from a recycled wastewater matrix was obtained. The micro-ITIES array was employed to study the ionophore-facilitated sulfate transfer at the W/NPOE interface using the ionophore 1,3-[Bis(3-phenylthioureidomethyl)]benzene, which has been used previously in ISEs and in the dropping electrolyte ITIES format $[17,24]$. The stoichiometry of the sulfate-ionophore complexe was determined electrochemically together with a complementary ESI-HRMS characterisation of complexes formed in W/NPOE emulsions. Finally, water samples from a water treatment plant were examined in an attempt to screen potential interferences that bind with the ionophore at the W/NPOE interface. 


\section{MATERIALS AND METHODS}

2.1. Reagents. All the reagents were purchased from Sigma-Aldrich Australia Ltd and used as received, unless otherwise indicated. The organic electrolyte (BTPPATPBCI) was prepared by metathesis of bis(triphenylphosphoranylidene)ammonium chloride (BTPPACl) and potassium tetrakis(4chlorophenyl)borate (KTPBCl), as reported previously [28]. BTPPATPBCI $(0.01 \mathrm{M})$ solutions were prepared in o-nitrophenyloctylether (NPOE) in the presence or absence of the commercial sulfate-ionophore I (S-I, 1,3-[Bis(3-phenylthioureidomethyl)]benzene) (Figure 1). All aqueous solutions $\left(\mathrm{Na}_{2} \mathrm{SO}_{4}\right.$ and $\mathrm{H}_{2} \mathrm{SO}_{4}$ ) were prepared in purified water, from a USF Purelab plus UV, with a resistivity of $18.2 \mathrm{M} \Omega \mathrm{cm}$.

2.2. Electrochemical cell. Electrochemical measurements were performed using an Autolab PGSTAT302N electrochemical analyser (Metrohm Autolab, Utrecht, The Netherlands). The electrochemical cell used is illustrated in Figure SI-1. The liquid-liquid interface was miniaturised by using silicon membranes containing 30 micropores of $22.4 \mu \mathrm{m}$ diameter [27]. These microporous membranes were sealed onto the lower orifice of a glass cylinder using a silicone rubber (Acetic acid curing glass silicone (Selleys Australia \& New Zealand)), (Figure SI-1a). The organic phase solution (yellow solution in Figure SI-1) was introduced into the silicon micropore array via the glass cylinder and the organic reference solution was placed on top of the organic phase. The silicon membrane was then immersed into the aqueous phase (Figure SI-1a,b). A two-electrode electrochemical cell was employed, whereby the micro-interface array was polarised by applying a potential difference between two electrodes ( $\mathrm{Ag}$ in the aqueous solution and $\mathrm{Ag} / \mathrm{AgCl}$ in the organic reference solution). Cyclic voltammetry (CV) was carried out at $10 \mathrm{mV} / \mathrm{s}$. Tetraethylammonium $\left(\mathrm{TEA}^{+}\right)$was used as an internal reference in order to determine the halfwave and formal transfer potentials on the Galvani potential scale using equation (1).

$$
\Delta_{o}^{w} \phi_{1 / 2, A^{z-}(\exp )}-\Delta_{o}^{w} \phi_{A^{z-}}^{o \prime}=\Delta_{o}^{w} \phi_{1 / 2, T E A^{+}(\exp )}-\Delta_{o}^{w} \phi_{T E A^{+}}^{o \prime}
$$

where $\Delta_{o}^{w} \phi_{A^{z-}}^{o \prime}$ and $\Delta_{o}^{w} \phi_{T E A^{+}}^{o \prime}$ are the formal transfer potentials of the anion $\mathrm{A}^{-}$and TEA ${ }^{+}$, respectively, and $\Delta_{o}^{w} \phi_{1 / 2, A^{z-}(\exp )}$ and $\Delta_{o}^{w} \phi_{1 / 2, T E A^{+}(\exp )}$ are the experimental half-wave potentials of $\mathrm{A}^{-}$and TEA ${ }^{+}$, respectively. $\Delta_{o}^{w} \phi_{T E A^{+}}^{o \prime}$ is $-3 \mathrm{mV}$ [28] based on the tetraphenylarsonium tetraphenylborate (TATB) assumption for W/NPOE interfaces.

Electrospray ionisation - high resolution mass spectrometry (ESI-HRMS). A high resolution LTQ XL Orbitrap mass spectrometer (Thermo Fisher Scientific Corporation, Waltham, USA) coupled to an electrospray ionisation source operated in positive and negative ion mode was employed to determine elemental formulae and accurate masses of the ionophore and its complexes. Emulsions of NPOE in aqueous phase $(1: 1, v: v)$ were formed by sonication and then diluted (ca. 1:4, v:v) with methanol. These emulsions were infused at $3-8 \mu \mathrm{L} \mathrm{min}^{-1}$ into the mass spectrometer using a built-in syringe pump. The emulsions contained the ionophore $\left(2.5 \times 10^{-3} \mathrm{M} \mathrm{S}-\mathrm{I}\right)$ and organic electrolyte (0.01 M BTPPATPBCl) to mimic the electrochemical cell conditions. Before each measurement, full calibration of the LTQ Orbitrap $X L$ in the $110-2000 \mathrm{~m} / \mathrm{z}$ range was conducted with the positive and negative ion calibration solutions provided by Thermo Scientific. For increased mass accuracy, a plasticizer interfering peak present in the background (n-butyl benzenesulfonamide, $\mathrm{C}_{6} \mathrm{H}_{5} \mathrm{SO}_{2} \mathrm{NH}\left(\mathrm{CH}_{2}\right)_{3} \mathrm{CH}_{3},[\mathrm{M}+\mathrm{H}]^{+}=214.0896 \mathrm{~m} / \mathrm{z}$ ), was used for the lock mass function. For increased sensitivity, electrospray and transfer lenses were optimised using a standard solution of caffeine prior to each batch of measurements. The screening analysis was conducted by operating the mass spectrometer in full-scan mode in the range $70-1000 \mathrm{~m} / \mathrm{z}$ with a mass resolution of 30.000 (@ $400 \mathrm{~m} / \mathrm{z}$ ). To gain structural information on the ionophore and its complexes, samples were 
also analysed by operating in $\mathrm{HRMS}^{2}$ mode, where the mass spectrometer was set to isolate the target parent compound, fragment it in the LTQ ion trap, and then scan for the product ions in the Orbitrap mass analyser. A mass resolution of 30.000 (@ $400 \mathrm{~m} / \mathrm{z}$ ) was used for the MS/MS experiments. For substance identification, the deviation of the measured mass (i.e. parent compound and fragments) was compared to the theoretical mass $(<5 \mathrm{ppm}$, relative error). The measured isotope pattern was also compared with that obtained from isotopic simulation. Data was processed using Xcalibur QualBrowser 2.0.7 SP1, from Thermo Fisher Scientific.

2.3. Water sample collection. Treated wastewater samples were collected from the Beenyup advanced water recycling plant, in Perth, Australia. In this plant, secondary-treated wastewater is further treated to drinking water standards before being recharged into the groundwater aquifer. The advanced water treatment process involves purification of the secondary-treated wastewater by ultrafiltration (UF) and reverse osmosis (RO), followed by disinfection with ultraviolet irradiation (UV) [31]. Water samples were collected from two different stages at the plant: (i) pre-RO and (ii) post-RO.

2.4. Ion chromatography (IC). Ion chromatography was performed on a Dionex ICS-90 ion chromatography system (Thermo Fisher Scientific Corporation, Waltham, USA). Anion separations were performed with a Dionex Ion Pac AS23 4 × 250 mm, which is chemically modified with alkanol quaternary ammonium salts, and ion detection was via conductivity measurement. The samples were prepared in 0.5 $\mathrm{mL}$ polyvials which contained a $0.45 \mu \mathrm{m}$ filter. The eluent was $18 \times 10^{-3} \mathrm{M}$ carbonate $/ 3.2 \times 10^{-3} \mathrm{M}$ bicarbonate, the regenerant was $50 \times 10^{-3} \mathrm{M}$ sulphuric acid, the flow rate was $1 \mathrm{~mL} \mathrm{~min} \mathrm{~m}^{-1}$ and the injection volume was $20 \mu \mathrm{L}$. The system also contained a guard column and a suppressor column (ARS $3004 \mathrm{~mm}$ ) to reduce the background conductivity of the eluent. For identification and quantification, five anion standard solutions $\left(\mathrm{Cl}^{-}, \mathrm{NO}_{2}{ }^{-}, \mathrm{NO}_{3}{ }^{-}, \mathrm{H}_{2} \mathrm{PO}_{4}{ }^{-}\right.$and $\left.\mathrm{SO}_{4}{ }^{2-}\right)$ were prepared between 0.1 and $100 \mathrm{ppm}\left(\mathrm{mg} \mathrm{L}^{-1}\right)$ (not shown here). The retention times were $6.66\left(\mathrm{Cl}^{-}\right), 8.22\left(\mathrm{NO}_{2}^{-}\right), 11.63\left(\mathrm{NO}_{3}{ }^{-}\right), 15.76\left(\mathrm{H}_{2} \mathrm{PO}_{4}{ }^{-}\right)$and 17.55 $\left(\mathrm{SO}_{4}{ }^{2-}\right) \mathrm{min}$. For all the ions studied, calibration curve linearity was observed between 0.1 and $100 \mathrm{ppm}$ ( $\mathrm{n}$ $=7)$. The pre-RO water sample was diluted with ultra-pure water $(1 / 20)$ prior to analysis.

\section{RESULTS AND DISCUSSION}

\subsection{Cyclic voltammetry of sulfate at W/NPOE micro-ITIES array}

Figure 1a illustrates the facilitated transfer of sulfate anions from the aqueous phase to the organic phase by the ionophore, with formation of the ionophore-sulfate complex under electrochemical control. In the absence of ionophore, but with added TEA ${ }^{+}$(for calibration of the potential axis), the voltammetry (Figure 1b) exhibited an as-expected signal for the TEA ${ }^{+}$transfer process [30] and a background electrolyte transfer indicated by the large negative current approaching $-0.6 \mathrm{~V}$. In the presence of ionophore (Figure 1c), the voltammetric behaviour exhibited an ion-transfer current in the region of $-0.4 \mathrm{~V}$, indicating a lower energy requirement for the transfer of ions than for the electrolyte in the absence of ionophore. By convention, a positive current is defined as a transfer of cation from aqueous phase to organic phase (see the $\mathrm{TEA}^{+}$transfer process in Figure $1 \mathrm{~b}$ ) or the transfer of an anion from the organic phase to the aqueous phase. Similarly, a negative current is defined as transfer of an anion for the aqueous phase to the organic phase of or a cation for the organic phase to the aqueous phase [31]. Hence the increase in current at ca. $-0.4 \mathrm{~V}$ is attributed to the ionophore-facilitated transfer of sulfate from water to organic phase (Figure 
1c). The data suggest an interfacial complexation between sulfate and the ionophore, with the latter diffusing to the interface, since its concentration in the organic phase $\left(2.5 \times 10^{-3} \mathrm{M}\right)$ is lower than the higher concentrations of sulfate examined $(0.1 \mathrm{M}, 0.01 \mathrm{M})$. The expected peak-shaped response due to linear diffusion of the ionophore within the micropores [30] is distorted by the background current signal. However, following background-subtraction for the $\mathrm{CVs}$ at $0.01 \mathrm{M} \mathrm{Na}_{2} \mathrm{SO}_{4}$ (Figure $1 \mathrm{c}$ inset), the voltammogram becomes peak-shaped with a peak height of $2.3 \mathrm{nA}$. The sulfate FIT process is considered to be chemically reversible, as is illustrated in Figure $1 \mathrm{c}$ by the current peak recorded when the potential scan direction is reversed from $-0.6 \mathrm{~V}$ towards more positive potentials. Furthermore the peak current $\left(i_{p}\right)$ associated with the FIT process was linearly dependent on the square root of the scan rate $(v)$, indicating a 1-dimensional diffusion-controlled process. For the forward scan, the linear response was expressed by the equation $i_{p}(\mathrm{nA})=-11.43 v^{1 / 2}\left(\mathrm{~V} \mathrm{~s}^{-1}\right)^{1 / 2}+0.08(\mathrm{nA}), \mathrm{R}^{2}=0.996$, while for the reverse scan the linear response was given by $i_{p}(n A)=27.62 v^{1 / 2}\left(V^{-1}\right)^{1 / 2}+1.22(n A), R^{2}=0.999$. For a linear diffusion process, the peak current is expected to be proportional to the square root of the scan rate $\left(v^{1 / 2}\right)$, according to the Randles-Sevcik equation, equation (2).

$$
i_{p}=2.69 \times 10^{5} z^{3 / 2} A C D^{1 / 2} v^{1 / 2}
$$

where $z$ is the charge of the transferring species, $A$ is the area of the interface, $C$ is the concentration and $D$ is the diffusion coefficient of the species controlling the transfer process.

If the diffusion coefficient of the ionophore or ligand $\left(D_{L}\right)$ is assumed to be equal to that of the complex, $D_{L-A^{z-}}$, then, using $\mathrm{z}=-2$, and concentration of ligand (ionophore) $C_{L}=1.25 \times 10^{-5} \mathrm{~mol} \mathrm{~cm}^{-3}$ in Eq. (2), $D_{L}$ is estimated to be $1.0 \times 10^{-8} \mathrm{~cm}^{2} \mathrm{~s}^{-1}$ (forward signal) and $6.1 \times 10^{-8} \mathrm{~cm}^{2} \mathrm{~s}^{-1}$ (reverse). Additionally, at a lower concentration of ionophore $\left(1.25 \times 10^{-6} \mathrm{~mol} \mathrm{~cm}^{-3}\right)$, the slope of the forward sweep for the ip $\alpha v^{1 / 2}$ plot was $-1.26 \mathrm{nA} \mathrm{V}^{-1 / 2} \mathrm{~s}^{1 / 2}$. Thus the ratio of the ionophore concentrations $\left(1.25 \times 10^{-5} / 1.25 \times 10^{-6}=10\right)$ matches the ratio of the slopes $(-11.43 /-1.26=9)$ as expected for linear diffusion (Eq. $(2)), i \alpha v^{1 / 2} C_{L}$, of a $1: 1$ complex [24].

The diffusion coefficient of the ionophore was also calculated in a similar manner as previously reported for dopamine [32] using the following expression for the limiting current $\left(i_{\text {lim }}\right)$ at an in-laid micro-interface array:

$$
i_{\text {lim }}=N 4 z F D C
$$

where for $N$ is the number of micro-interfaces (30 in this case), $F$ is Faraday's constant, $r$ is the radius of each independent interface $\left(1.12 \times 10^{-3} \mathrm{~cm}^{2}\right)$ and $C$ is the bulk concentration of the ionophore $\left(2.5 \times 10^{-6}\right.$ mol cm$\left.{ }^{-3}\right)$. The estimated $D_{L}$ with this approach was $3.6 \times 10^{-8} \mathrm{~cm}^{2} \mathrm{~s}^{-1}$, in agreement with the above approach. These values are two orders of magnitude lower than the values reported for the ionophore dibenzo-18-crown-6 (DB18C6) in 1,2-dichloroethane (DCE) [32] but in good agreement with $D_{L}$ data reported for neutral ionophores in 33\% PVC-NPOE membranes (e.g. ca. $1.5 \times 10^{-8} \mathrm{~cm}^{2} \mathrm{~s}^{-1}$ ) [33]. 
a)

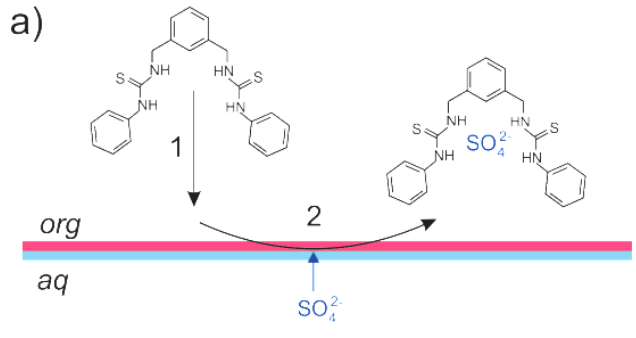

b)

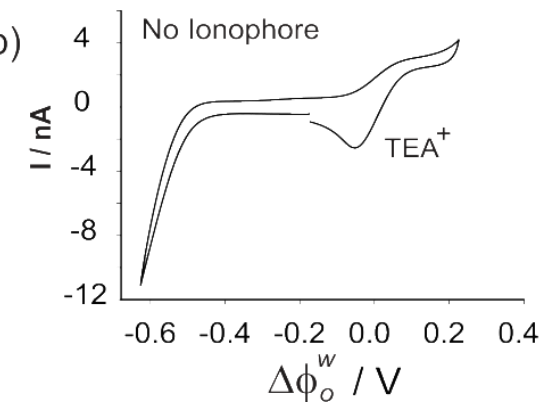

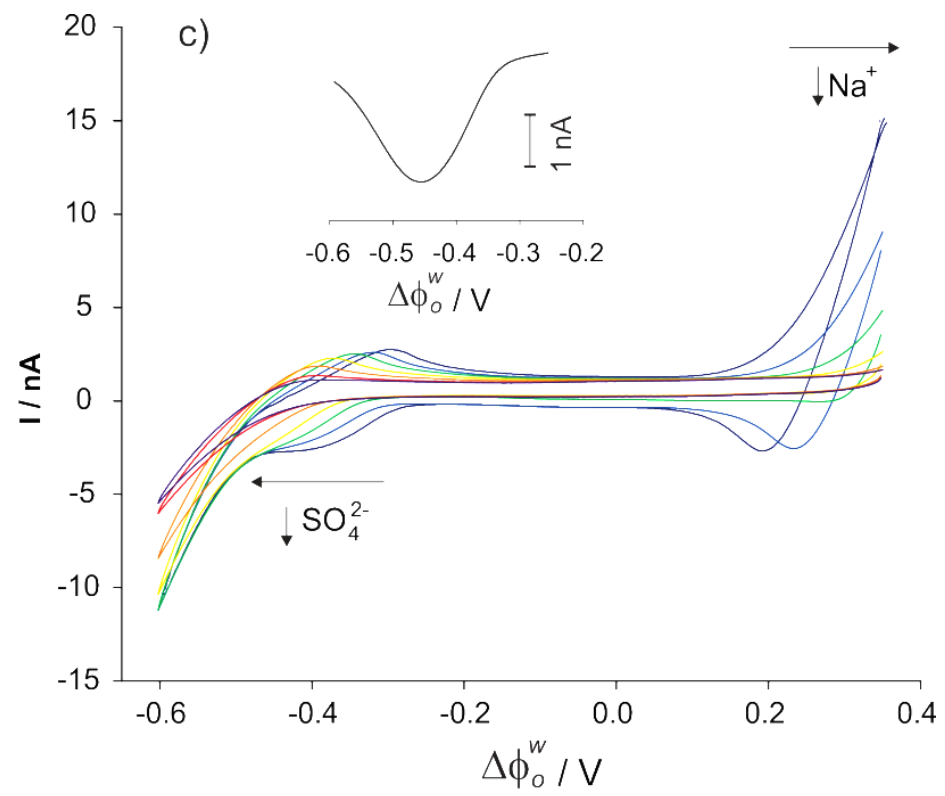

Figure 1. a) Schematic diagram of the facilitated sulfate transfer process: (1) Diffusion of the ionophore in the organic phase and (2) facilitated transfer via interfacial complexation. b) CV of $0.01 \mathrm{M} \mathrm{Na}_{2} \mathrm{SO}_{4}+20 \mathrm{x}$ $10^{-6} \mathrm{M} \mathrm{TEA}^{+}$in the absence of the ionophore in the organic phase (NPOE). c) CV of different $\mathrm{Na}_{2} \mathrm{SO}_{4}$ concentrations $\left(10^{-7}, 10^{-6}, 10^{-5}, 10^{-4}, 10^{-3}, 10^{-2}, 10^{-1} \mathrm{M}\right)$ in the presence of $2.5 \times 10^{-3} \mathrm{M}$ sulfate-ionophore I in the organic phase (NPOE); in part c, as sulfate concentration decreased, the transfer wave shifted to the left (towards more negative potentials); as sodium concentration decreased, the current on the upper right hand side shifted to the right. Scan rate: $10 \mathrm{mV} \mathrm{s}^{-1}$.

As shown by Figure $1 \mathrm{c}$, as concentration of $\mathrm{Na}_{2} \mathrm{SO}_{4}$ was varied, the sulfate transfer wave shifted to more positive potentials. We note here that the potential scale was calibrated to the Galvani scale by addition of $\mathrm{TEA}^{+}$at the end of each series of experiments. Hence the shift in potential is not an artefact of the reference electrode potential. By measuring the half-wave potential as a function of the $\mathrm{Na}_{2} \mathrm{SO}_{4}$ concentration, and by selecting the potential value at a fixed current of $-1.25 \mathrm{nA}$ (which corresponds to half the wave current at the highest sulfate concentration) (Figure 2a), a Nernstian response of $28.4 \mathrm{mV}$ $\operatorname{dec}^{-1}$ was found (Figure $2 \mathrm{~b}$ ). This indicates a transfer of a doubly-charged anion, i.e. $\mathrm{SO}_{4}{ }^{2-}$ and the formation of 1:1 sulfate-ionophore complex, as other sulfate-to-ionophore ratios would produce a different response slope. Performance of nine measurements via cyclic voltammetry on separate days with freshly prepared organic phase solutions provided a relative standard deviation (RSD) of $16 \%$ for the current signal (mean $=2.5 \mathrm{nA}$, standard deviation $=0.4 \mathrm{nA}$, at $0.01 \mathrm{M} \mathrm{Na}_{2} \mathrm{SO}_{4}$ ) and a standard deviation of $4.8 \mathrm{mV} \mathrm{dec}^{-1}$ and average slope of $29.6 \mathrm{mV} \mathrm{dec}^{-1}$ in the sensitivity (slope of half-wave potential $\left(\Delta_{o}^{w} \phi_{1 / 2}\right)$ versus the ( $\left.\log C_{S_{4}^{2-}}^{w}\right)$ plot). Additionally, a single array with $30 \mathrm{~W} / \mathrm{NPOE}$ micro-interfaces was assessed during 11 days storage in high purity de-ionised water and its response to $0.01 \mathrm{M} \mathrm{Na}_{2} \mathrm{SO}_{4}$ measured every $24 \mathrm{~h}$. In this case, the current data showed a 16\% RSD over this time period. The mean LOD calculated for $\mathrm{SO}_{4}{ }^{2-}$ by cyclic voltammetry was $1.3( \pm 0.9) \times 10^{-6} \mathrm{M}\left(125 \mathrm{ng} \mathrm{ml}^{-1}\right)$ for $\mathrm{n}=9$ (Table SI-1) whilst the LOD from

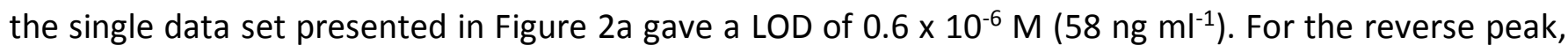
the CVs show a slope of $24.2 \pm 3.6 \mathrm{mV} \mathrm{dec}^{-1}$ with a LOD of $2.0( \pm 3.1) \times 10^{-6} \mathrm{M}\left(192 \mathrm{ng} \mathrm{ml}^{-1}\right)$ sulfate.

The LOD here is defined as the intersection of the line of best fit of the linear range $\left(\Delta_{\boldsymbol{o}}^{w} \phi_{1 / 2}\right.$ vs $\left.\log C_{\mathrm{SO}_{4}^{2-}}^{w}\right)$ with the horizontal line [34] (Figure 2b). This procedure was also applied to the current data after 
background-subtraction of the voltammograms (Figure 2c). Figure $2 \mathrm{~d}$ illustrates the peak current obtained from the background-subtracted voltammograms of Figure $2 \mathrm{c}$. The LOD was $14 \times 10^{-6} \mathrm{M}\left(1344 \mathrm{ng} \mathrm{ml}^{-1}\right)$ for the forward peak and $0.8 \times 10^{-6} \mathrm{M}\left(77 \mathrm{ng} \mathrm{ml}^{-1}\right)$ for the reverse peak, which are larger than the value obtained from Figure $2 \mathrm{~b}\left(0.6 \times 10^{-6} \mathrm{M}, 58 \mathrm{ng} \mathrm{ml}^{-1}\right)$ because the measurement of the peak current becomes more challenging at low concentrations of sulfate. Aqueous phase sulfuric acid was also investigated (107 to $10^{-1} \mathrm{M}, 10-10^{7} \mathrm{ng} \mathrm{ml}^{-1}$ ) to evaluate the response in acidic conditions. Figure $\mathrm{SI}-2 \mathrm{a}$ shows analogous voltammetry for various $\mathrm{H}_{2} \mathrm{SO}_{4}$ concentrations as observed for $\mathrm{Na}_{2} \mathrm{SO}_{4}$, with no clear impact of the acidity on the amperometric and potential signals (Figure $\mathrm{SI}-2 \mathrm{~b}$ ).

a)

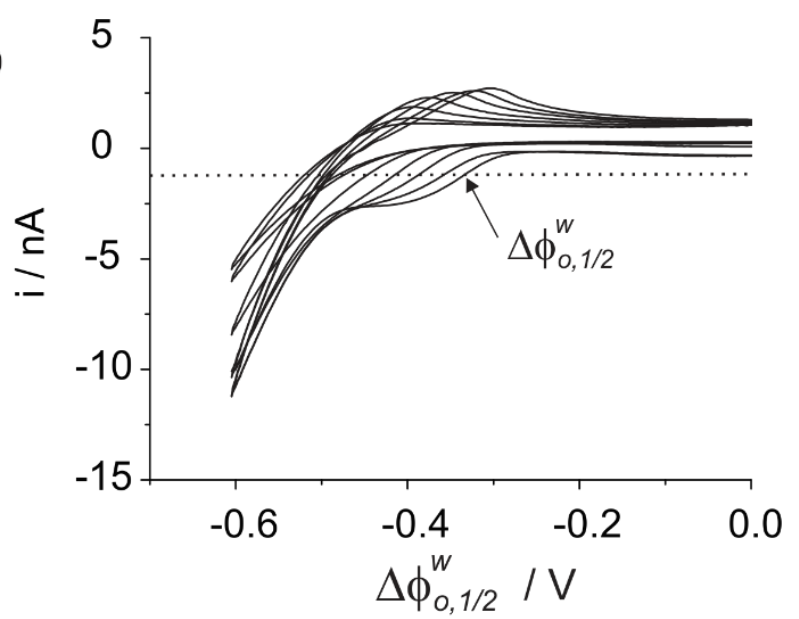

c)

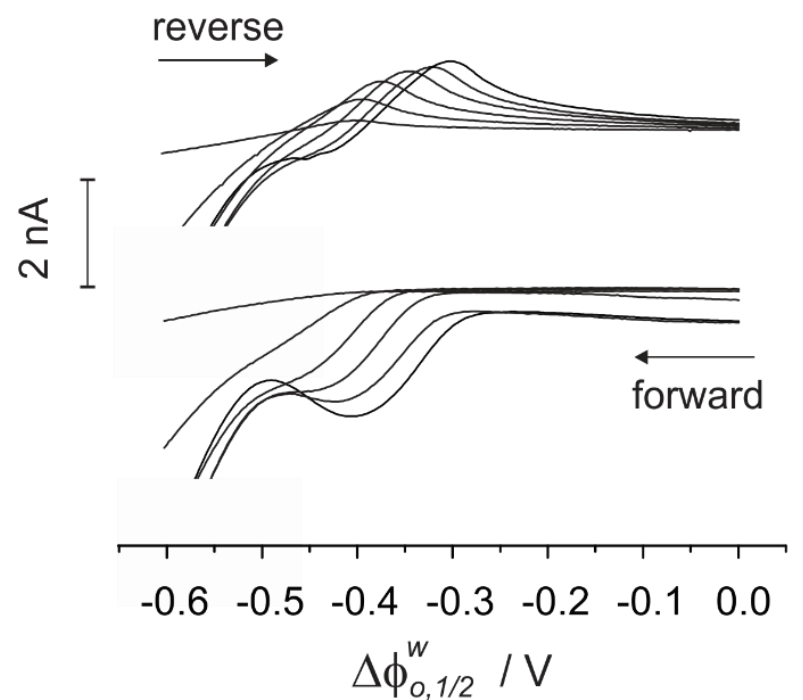

b)

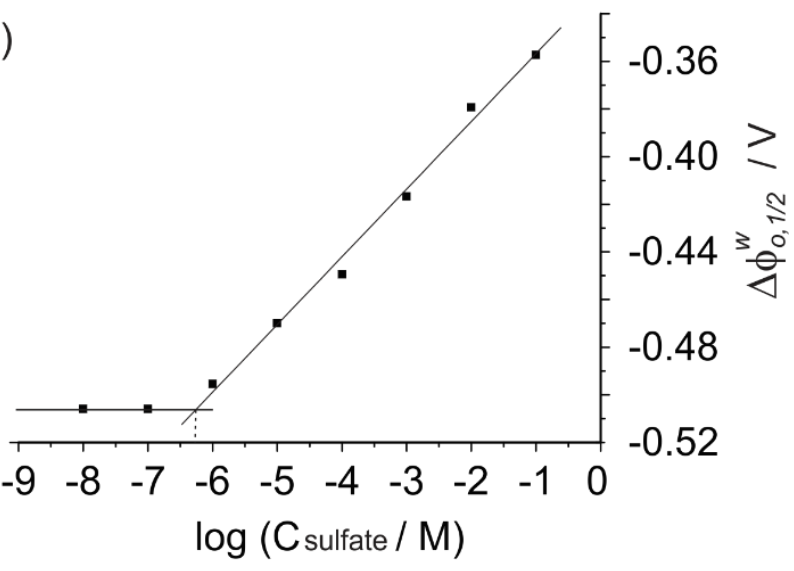

d)

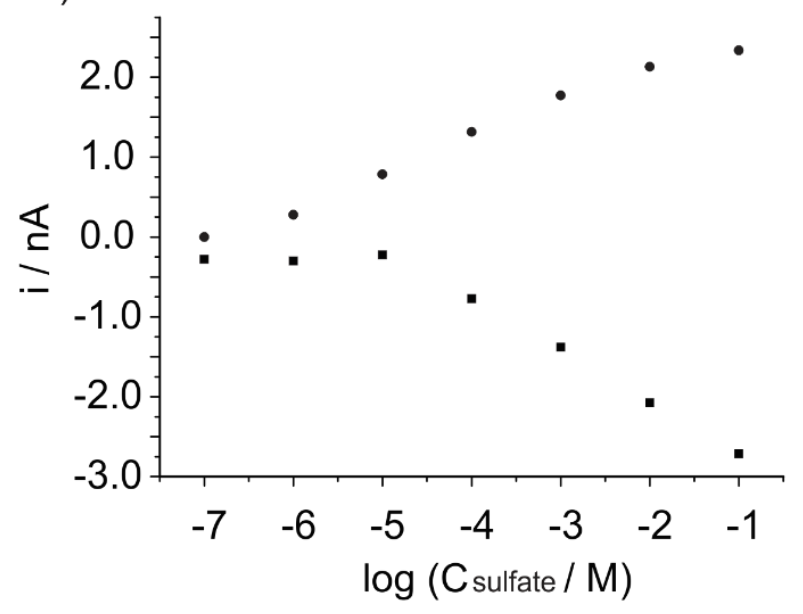

Figure 2. a) $\mathrm{CV}$ of different aqueous phase $\mathrm{Na}_{2} \mathrm{SO}_{4}$ concentrations. b) Plot of half-wave potential ( $\left.\Delta_{o}^{w} \phi_{1 / 2}\right)$ measured from CVs in Figure 2 a versus logarithm of sulfate concentration ( $\log \left(C_{\text {sulfate }} / \mathrm{M}\right)$. c) CV of different $\mathrm{Na}_{2} \mathrm{SO}_{4}$ concentrations after background (CV in the absence of sulfate) subtraction. d) Plot of peak height from Figure $2 \mathrm{c}$ versus $\log \left(C_{\text {sulfate }} / \mathrm{M}\right)$ for different $\mathrm{Na}_{2} \mathrm{SO}_{4}$ concentrations. Organic phase: 2.5 $x 10^{-3} \mathrm{M}$ sulfate-ionophore in NPOE $+0.01 \mathrm{M}$ BTPPATPBCl; scan rate: $10 \mathrm{mV} \mathrm{s}^{-1}$. 


\subsection{Electrospray ionisation - high resolution mass spectrometry (ESI-HRMS) of W/NPOE emulsions}

There are several reports about the use of biphasic ESI-HRMS as a complementary technique to voltammetry for the characterisation of interfacial complexes formed at the ITIES. The majority of this work focuses on cation complexation (e.g., alkali metals [35,26], $\mathrm{Rb}^{+}$[37], $\mathrm{Cs}^{+}$[38] and $\mathrm{Sr}^{2+}$ [39]). Since the electrochemical data discussed above revealed the FIT of sulfate at W/NPOE micro-interfaces, ESI-HRMS was implemented in order to characterise the nature of the sulfate-ionophore complexes formed at these interfaces.

Firstly, the ionophore was prepared in water:methanol (50:50, v:v) and sprayed directly into the MS using an ESI source operated in positive or negative ion mode. The anionic form of the ionophore (i.e., negative ion mode, $[\mathrm{M}-\mathrm{H}]^{-}$) showed a mass-to-charge ratio of $405.1202 \mathrm{~m} / \mathrm{z}$, while the protonated form (i.e., positive ion mode, $[\mathrm{M}+\mathrm{H}]^{+}$) showed a peak at $407.1353 \mathrm{~m} / \mathrm{z}$. These values agree with the molecular formula of the ionophore $\left(\mathrm{C}_{22} \mathrm{H}_{22} \mathrm{~N}_{4} \mathrm{~S}_{2}\right)$ after subtraction or addition of a charge with a relative error of 0.629 or $-1.362 \mathrm{ppm}$, respectively. This procedure was also followed with the organic phase solution used in the electrochemical experiments, i.e. ionophore + organic electrolyte + NPOE. In this case, the mixture of $2.5 \mathrm{mM}$ ionophore $+10 \mathrm{mM}$ organic electrolyte + NPOE was diluted $(1: 4, \mathrm{v}: \mathrm{v})$ in methanol to facilitate sample electrospray ionisation. In negative ion mode, the organic solvent ( $\left.\mathrm{NPOE}^{-}\right)$, ionophore $\left(\left[\mathrm{SI}^{-}\right]^{-}\right)$and the organic electrolyte anion ( $\mathrm{TPBCl}^{-},\left[\mathrm{C}_{24} \mathrm{H}_{16} \mathrm{BCl}_{4}\right]^{-}$) were identified at $\mathrm{m} / \mathrm{z}$ values of $251.1521,405.1202$ and 457.0089, respectively. In positive mode, peaks in the spectrum at 274.1406, 407.1353 and 538.1841 $m / z$ corresponded to the solvent $\left([\mathrm{NPOE}+\mathrm{Na}]^{+}\right)$, the protonated ionophore $\left(\left[\mathrm{C}_{22} \mathrm{H}_{22} \mathrm{~N}_{4} \mathrm{~S}_{2}+\mathrm{H}\right]^{+}\right)$and the organic electrolyte cation (BTPPA $\left.{ }^{+},\left[\mathrm{C}_{36} \mathrm{H}_{30} \mathrm{NP}_{2}\right]^{+}\right)$.

This approach was undertaken to identify sulfate-ionophore complexation in methanol:water solutions and methanol:water/NPOE emulsions (see Figure 3a-b). The emulsion corresponds to $0.1 \mathrm{M}$ sulfate in the aqueous phase and $2.5 \mathrm{mM}$ ionophore in the NPOE phase $(1: 1, \mathrm{v}: \mathrm{v})$ and was diluted in methanol $(1: 4, \mathrm{v}: \mathrm{v})$ to aid ionisation. In the spectra presented in Figure 3, a new peak appeared at ca. $503 \mathrm{~m} / \mathrm{z}$ which was not seen in the absence of sulfate. This value corresponds to the mass of a 1:1 ionophore:hydrogen sulfate complex formed in the emulsion medium, which confirms the interaction between the neutral ionophore S-I and sulfate ions. 


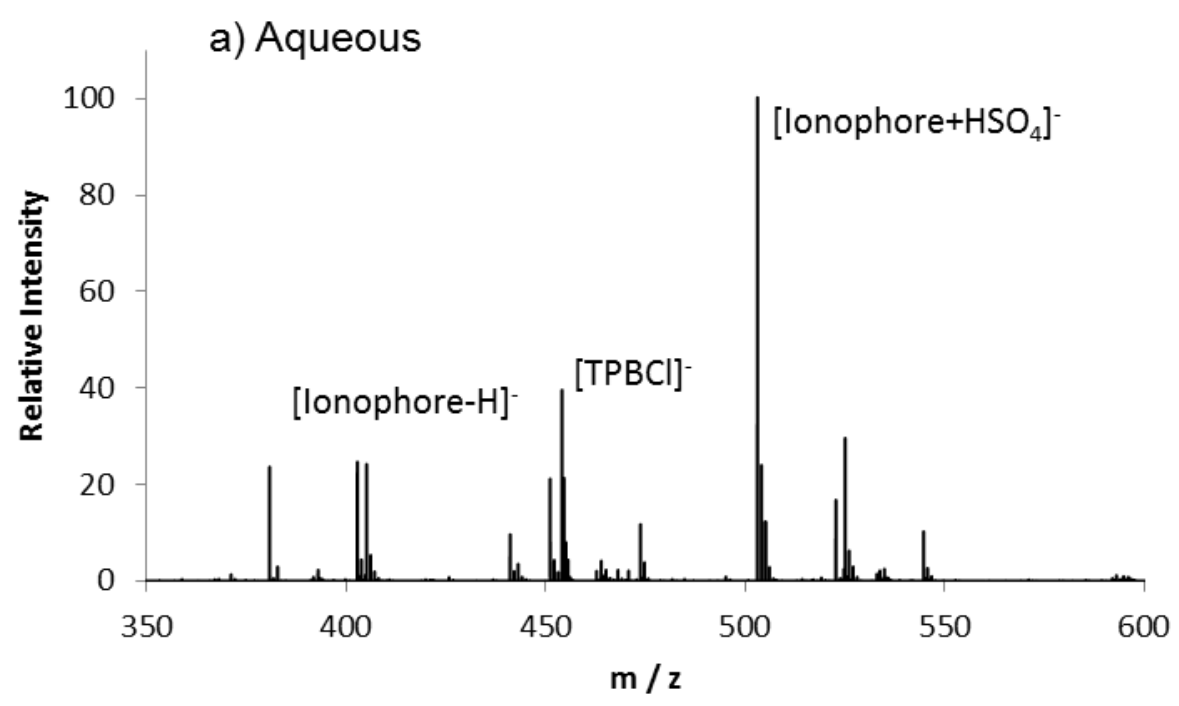

b) W/NPOE emulsion

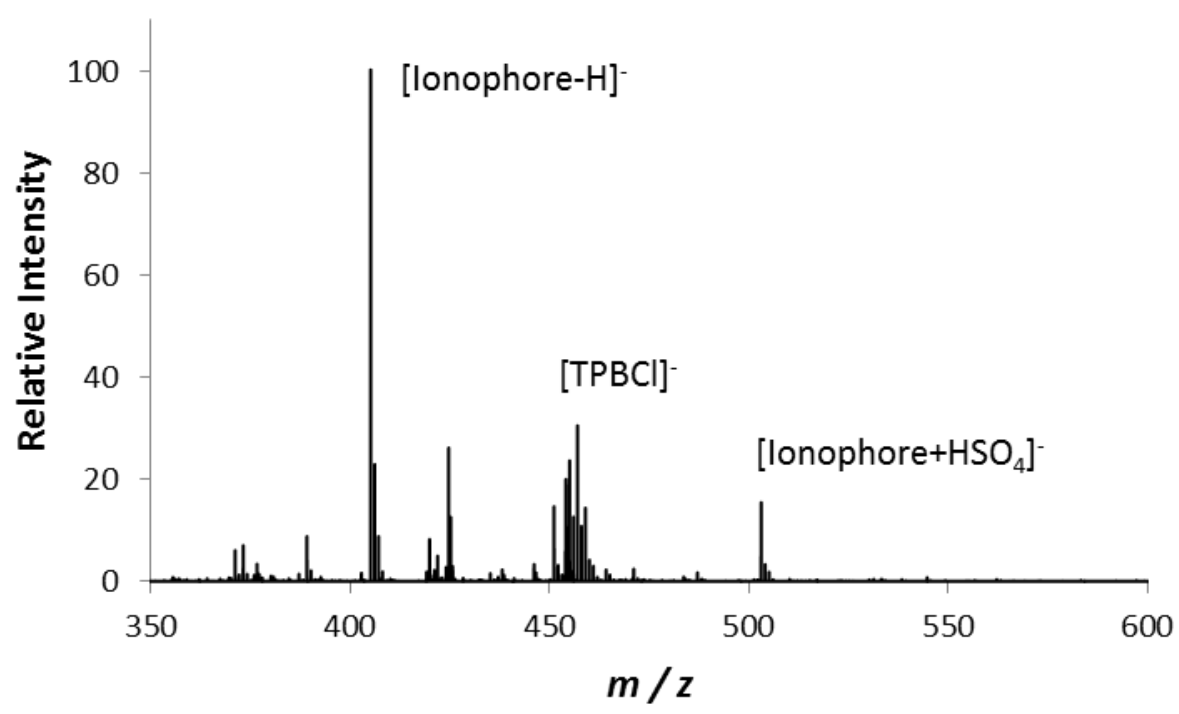

Figure 3. Mass spectra of a) ionophore with an excess of sulfate ( $\left.0.1 \mathrm{M} \mathrm{Na}_{2} \mathrm{SO}_{4}\right)$ in water:methanol (50:50, $\mathrm{v}: \mathrm{v})$ and $\mathrm{b}$ ) emulsion formed from $2.5 \mathrm{mM}$ ionophore $+10 \mathrm{mM} \mathrm{BTPPATPBCl}$ in NPOE with aqueous sulfate $\left(0.1 \mathrm{M} \mathrm{Na}_{2} \mathrm{SO}_{4}\right)$ in water, diluted in methanol $(1: 4, \mathrm{v}: \mathrm{v})$ prior to introduction into the MS.

The theoretical and experimental ionophore:hydrogen sulfate (1:1) complex $\mathrm{m} / \mathrm{z}$ ratios from Figure 3a-b are summarised in Table 1 together with the relative errors. These ratios correspond to $\left[\mathrm{C}_{22} \mathrm{H}_{23} \mathrm{~N}_{4} \mathrm{~S}_{3} \mathrm{O}_{4}\right]^{-}$ ([ionophore- $\left.\left.\mathrm{HSO}_{4}\right]^{-}\right)$, a 1:1 complex with only one negative charge, because small molecules tend to present low charge states in MS spectra. The larger relative intensity of the [ionophore $\left.+\mathrm{HSO}_{4}\right]^{-}$peak in the aqueous medium (Figure 3a) compared to the emulsion spectrum (Figure $3 b$ ) indicates a decrease in the ability of the ionophore to complex sulfate from the aqueous phase which could arise from differences in its solubility and in the orientation of the $\mathrm{H}$-bonds from the two thiourea moieties. Table 1 illustrates the differences between the theoretical and experimental $m / z$ ratios for the ionophore-sulfate complex, displaying an excellent agreement (relative error $<5 \mathrm{ppm}$ ). 
Table 1. Summary of the theoretical and experimental $m / z$ determined by ESI-HRMS for the sulfate ionophore-sulfate complex (ionophore: $\mathrm{HSO}_{4}^{-}$) in aqueous medium and W/NPOE emulsions.

\begin{tabular}{l|c|c|c|c}
\hline Sample description & Molecular formula & $\begin{array}{c}\text { Theoretical } \\
\text { value }(\mathbf{m} / \mathbf{z})\end{array}$ & $\begin{array}{c}\text { Experimental } \\
\text { value }(\boldsymbol{m} / \mathbf{z})\end{array}$ & $\begin{array}{c}\text { Relative } \\
\text { error } \\
/ \mathbf{p p m}\end{array}$ \\
\hline $\begin{array}{l}\text { [ionophore+HSO} \\
\text { MeOH: } \mathrm{H}_{2} \mathrm{O} \text { (Aqueous) }\end{array}$ & {$\left[\mathrm{C}_{22} \mathrm{H}_{23} \mathrm{~N}_{4} \mathrm{~S}_{3} \mathrm{O}_{4}\right]^{-}$} & 503.0876 & 503.0870 & -1.121 \\
\hline $\begin{array}{l}\text { [ionophore+HSO } \\
\text { MeOH: } \mathrm{H}_{2} \mathrm{O} / \mathrm{NPOE} \text { (Emulsion) }\end{array}$ & {$\left[\mathrm{C}_{22} \mathrm{H}_{23} \mathrm{~N}_{4} \mathrm{~S}_{3} \mathrm{O}_{4}\right]^{-}$} & 503.0876 & 503.0872 & -0.374 \\
\hline
\end{tabular}

*Relative error $(p p m)=\left(\Delta m \times 10^{6}\right) / m$ where $m$ is the theoretical mass and $\Delta m$ the difference between the theoretical and experimental

\subsection{Study of pre- and post-RO samples from an advanced water recycling plant}

\subsubsection{ESI-HRMS}

Monitoring of sulfate levels before (pre-) and after (post-) reverse osmosis treatment can provide valuable information on membrane performance and system integrity $[40,41]$. Since sulfate is added to the water treatment process as sulfuric acid for $\mathrm{pH}$ adjustment, it can be used as an indicator of system performance. Hence, knowledge of water sample component interactions with sensor constituents, specifically the ionophore, is of interest and can be achieved by use of ESI-HRMS as a simple screening approach.

Pre-RO and post-RO samples not only present significant differences in their sulfate content but also in their total anionic compositions. ESI-HRMS can help to identify species which have an affinity for the bisthiourea ionophore present in the W/NPOE emulsions. Figure 4 illustrates the behaviour of the W/NPOE emulsions with pre-RO (Figure 4a) and post-RO (Figure 4b) samples used as the aqueous phase. In Figure 4a, five peaks were identified, corresponding to the organic electrolyte anion, the ionophore, and three ionophore complexes formed with chloride, nitrate and sulfate. However for the post-RO sample, in which total ion concentration is lower, peaks were observed corresponding to the organic electrolyte anion ([TPBCl $\left.]^{-}\right)$and, with a significantly lower intensity, an ionophore-chloride complex (Figure 4b, inset) at $441.0975 \mathrm{~m} / \mathrm{z}$. This reduction in the intensity of the peaks is directly related to the concentration of ions in the sample. The mass and relative peak intensities of the species identified via ESI-HRMS (Figure 4) are summarised in Table 2 . The predominant complex was found to be [ionophore- $\mathrm{Cl}]^{-}(71 \%)$, greater than ionophore complexes with nitrate and sulfate in the pre-RO sample. 
a)

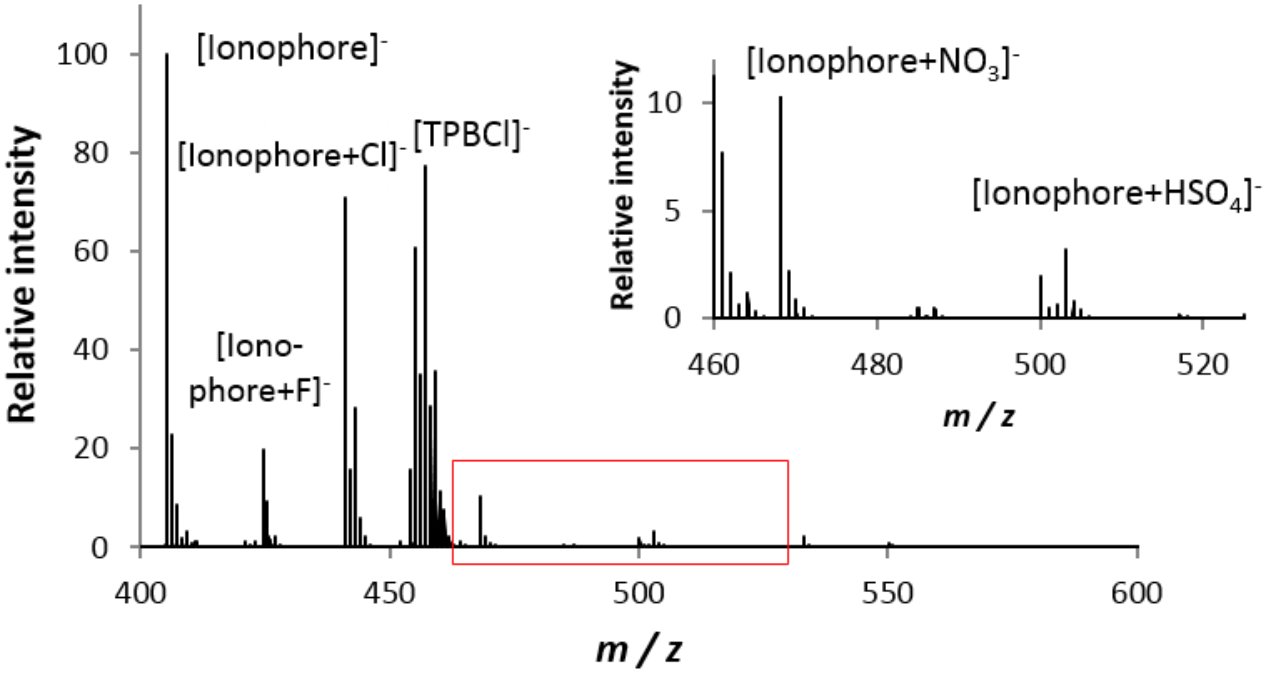

b)

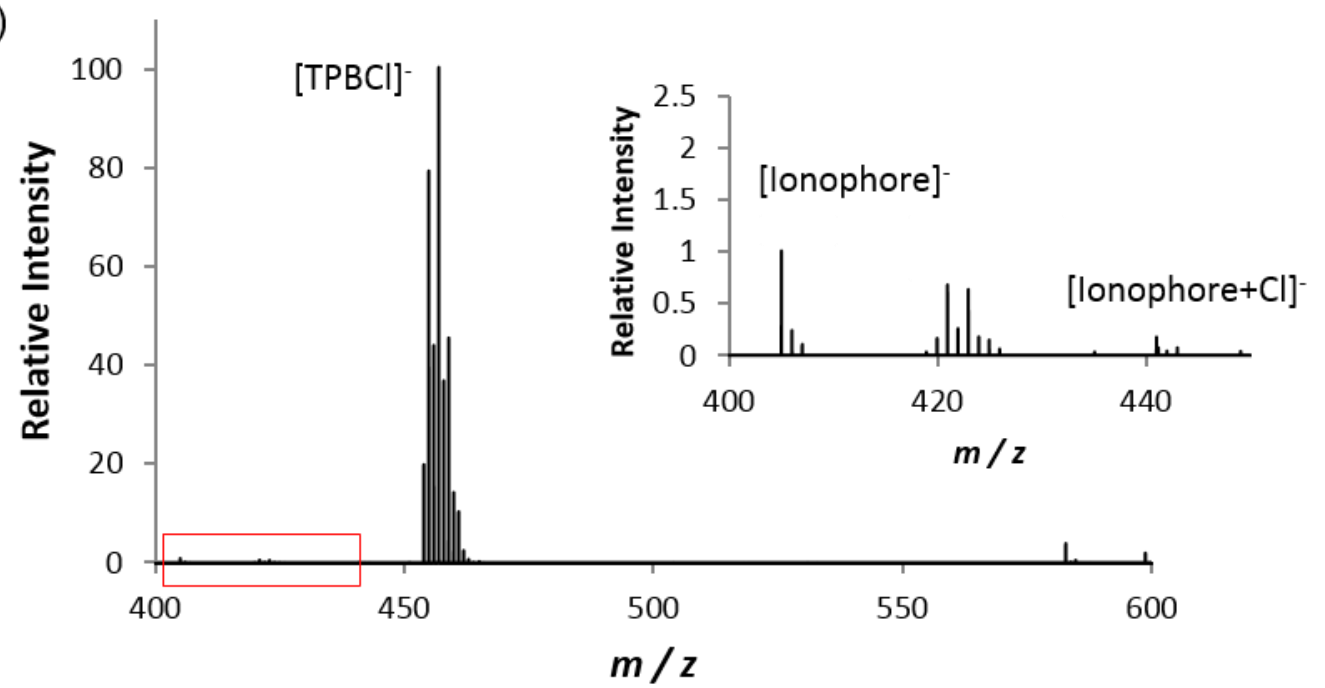

Figure 4. Spectra of W/NPOE emulsions where the water phase is the pre-RO water sample (a) or postRO water sample (b). The organic phase consisted of $2.5 \mathrm{mM}$ ionophore $+10 \mathrm{mM}$ BTPPATPBCl in NPOE. Insets are magnifications of the rectangular areas.

Table 2. Summary of the theoretical (Theo.) and experimental (Exp.) $m / z$ values determined by ESI-HRMS for the ionophore-anion complexes formed in W/NPOE emulsions with pre- and post-RO water samples. Rel. Int.: relative intensity.

\begin{tabular}{|c|c|c|c|c|c|c|}
\hline \multirow[b]{2}{*}{ Complex } & \multirow{2}{*}{$\begin{array}{l}\text { Elemental } \\
\text { formula }\end{array}$} & \multirow{2}{*}{$\begin{array}{l}\text { Theo. } \\
(m / z)\end{array}$} & \multicolumn{2}{|c|}{ pre-RO } & \multicolumn{2}{|c|}{ post-RO } \\
\hline & & & $\operatorname{Exp} .(m / z)$ & Rel. Int. & $\operatorname{Exp} .(m / z)$ & $\begin{array}{l}\text { Rel. } \\
\text { Int. }\end{array}$ \\
\hline [ionophore-H] ${ }^{-}$ & {$\left[\mathrm{C}_{22} \mathrm{H}_{21} \mathrm{~N}_{4} \mathrm{~S}_{2}\right]^{-}$} & 405.1202 & 405.1200 & 100.0 & 405.1200 & 1.0 \\
\hline${\text { [ionophore }+\mathrm{F}]^{-}}^{-}$ & {$\left[\mathrm{C}_{22} \mathrm{H}_{22} \mathrm{~N}_{4} \mathrm{~S}_{2} \mathrm{~F}\right]^{-}$} & 425.1264 & 425.1205 & 7.2 & - & - \\
\hline [ionophore+Cl] & {$\left[\mathrm{C}_{22} \mathrm{H}_{22} \mathrm{~N}_{4} \mathrm{~S}_{2} \mathrm{Cl}\right]^{-}$} & 441.0970 & 441.0978 & 70.9 & 441.0975 & 0.1 \\
\hline [ionophore $\left.+\mathrm{NO}_{3}\right]^{-}$ & {$\left[\mathrm{C}_{22} \mathrm{H}_{22} \mathrm{~N}_{5} \mathrm{~S}_{2} \mathrm{O}_{3}\right]^{-}$} & 468.1159 & 468.1152 & 10.3 & - & - \\
\hline [ionophore+HSO$\left.]_{4}\right]^{-}$ & {$\left[\mathrm{C}_{22} \mathrm{H}_{23} \mathrm{~N}_{4} \mathrm{~S}_{3} \mathrm{O}_{4}\right]^{-}$} & 503.0876 & 503.0870 & 3.1 & - & - \\
\hline$\left[\text { [ionophore }+\mathrm{H}_{2} \mathrm{PO}_{4}\right]^{-}$ & {$\left[\mathrm{C}_{22} \mathrm{H}_{24} \mathrm{~N}_{4} \mathrm{~S}_{2} \mathrm{PO}_{4}\right]^{-}$} & 503.0971 & - & - & - & - \\
\hline
\end{tabular}




\subsubsection{IC analysis}

Ion chromatography was performed to identify the anion composition in the pre-RO and post-RO samples, as ESI-HRMS revealed complexation of the ionophore with fluoride, chloride and nitrate, as well as sulfate (Figure 4; Table 2). These samples were analysed after the analysis of standard mixtures (see experimental section), thus allowing the identification and quantification of the anions present (Figure 5). Figure 5a shows four peaks in the chromatograms which correspond to chloride (6.66 $\mathrm{min}$ ), nitrate (11.63 $\mathrm{min}$ ), phosphate $(15.81 \mathrm{~min})$ and sulfate $(17.55 \mathrm{~min})$ based on the retention times of the standards. The fifth peak at $4.17 \mathrm{~min}$ might correspond to fluoride, although this was not investigated further. Hence, the presence of chloride, nitrate and sulfate match the ESI-HRMS data ( $c a .71$ and $10 \%$ relative intensity of [ionophore $+\mathrm{Cl}]^{-}$and [ionophore $\left.+\mathrm{NO}_{3}\right]^{-}$peaks, respectively) generated for the pre- $\mathrm{RO}$ sample. For the postRO sample, the concentrations of chloride and nitrate were considerably lower, $10.9 \mathrm{ppm}$ (ca. $0.2 \times 10^{-3}$ $\mathrm{M}$ ) and $8.7 \mathrm{ppm}$ (ca. $\left.0.1 \times 10^{-3} \mathrm{M}\right)$, respectively. In the post-RO water, the [ionophore $\left.+\mathrm{Cl}\right]^{-}$complex was the only one determined via ESI-HRMS. Thus, based on the data obtained from IC and ESI-HRMS, chloride, nitrate and, possibly, fluoride are the most likely competitors with sulfate for complexation with the bisthiourea ionophore in RO water samples.
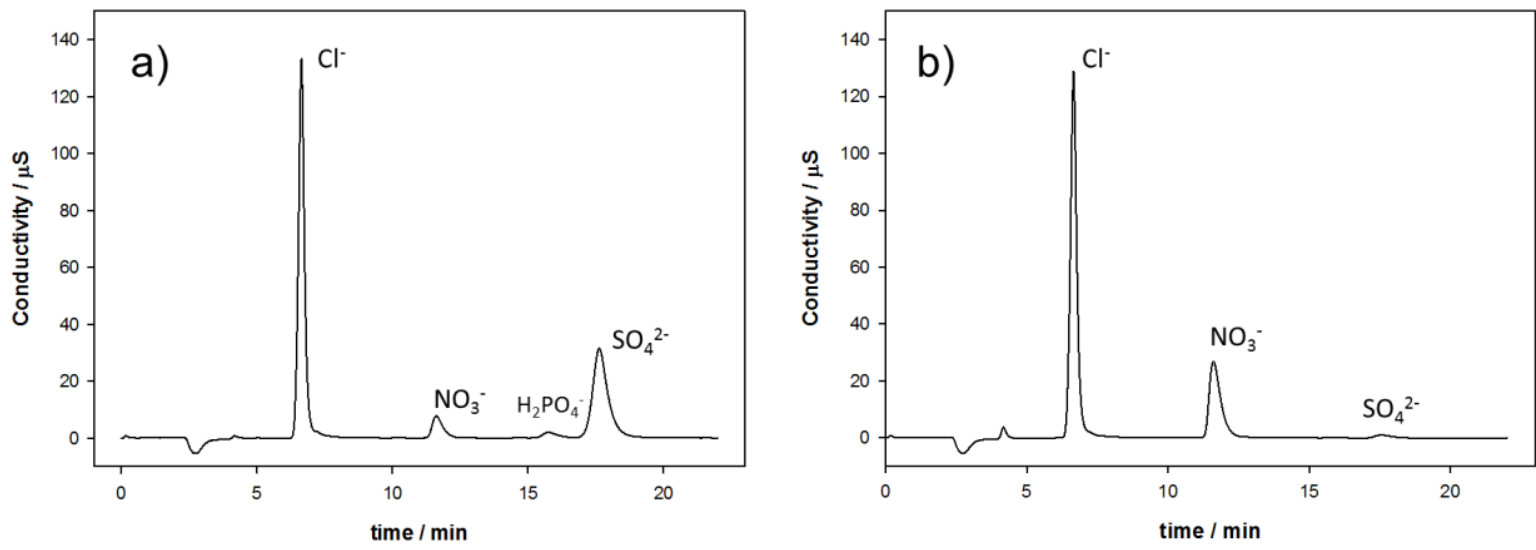

Figure 5. Ion chromatograms of a diluted (1/20) pre-RO water sample (a) and a post-RO water sample (undiluted) (b).

\section{CONCLUSIONS}

Interfacial sulfate association with a neutral ionophore (bis-thiourea ionophore) was investigated via cyclic voltammetry at a W/NPOE micro-interface array. Under an excess of the anion in the aqueous phase versus the ligand concentration in NPOE, Nernstian behaviour was achieved $(29.6 \mathrm{mV} \mathrm{dec}-1, z=-2)$ for this facilitated ion transfer process. Applying the IUPAC recommendations to determine the limit of detection

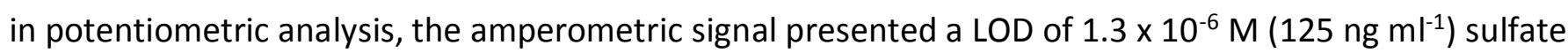
$(n=9)$ which is similar to ion chromatography detection limits $\left(\geq 1.5 \times 10^{-6} \mu \mathrm{M}\left(144 \mathrm{ng} \mathrm{ml}^{-1}\right)\right.$ [6]. An analysis of the sulfate transfer CVs showed that the ionophore diffusion in the organic phase was the controlling factor. The electrochemical data revealed the formation of 1:1 sulfate:ionophore complex and this was further confirmed via ESI-HRMS analysis of W/NPOE emulsions ([ionophore+HSO $\left.]_{4}\right]^{-}$). From the ESI-HRMS spectra of the W/NPOE emulsions prepared with water samples collected from an advanced water 
recycling plant, three peaks assigned respectively to [ionophore- $\mathrm{Cl}]^{-}$, [ionophore- $\left.\mathrm{NO}_{3}\right]^{-}$and [ionophore+F] accompanied the [ionophore- $\left.\mathrm{HSO}_{4}\right]^{-} \mathrm{m} / \mathrm{z}$ signal. Whilst phosphate was detected by ion chromatography in the pre-RO water sample, no signal corresponding to a [ionophore $\left.+\mathrm{H}_{2} \mathrm{PO}_{4}\right]^{-}$complex was detected by ESI-HRMS. These results demonstrate the potential of amperometric analysis and ESI-HRMS to screen interfacial ion-complexation processes as a step in the design and development of new receptors and ion sensing platforms. Based on the data presented here, future selectivity studies over anions such as chloride, nitrate and fluoride and the use of more sensitive electrochemical techniques will be pursued in order to develop an ITIES-based sulfate sensor.

\section{Acknowledgements}

This research was funded by the Australian Water Recycling Centre of Excellence through the Australian Government's National Urban Water and Desalination Plan.

\section{REFERENCES}

[1] N. Busschaert, C. Caltagirone, W. Van Rossom, P.A. Gale, Applications of supramolecular anion recognition, Chem. Rev., 115 (2015) 8038-8155.

[2] P.D. Beer, P.A. Gale, Anion recognition and sensing: The state of the art and future perspectives, Angew. Chem. Int. Ed., 40 (2001) 486-516.

[3] R.L. Hopkins, B.M. Altier, D. Haselman, A.D. Merry, J.J. White, Exploring the legacy effects of surface coal mining on stream chemistry, Hydrobiologia, 713 (2013) 87-95.

[4] M.I. Ojovan, W.E. Lee, An Introduction to Nuclear Waste Immobilisation, 2nd ed., Elsevier, Oxford, 2013.

[5] T. Nakanishi, Y. Otaki, Y. Hasuike, M. Nanami, R. Itahana, K. Miyagawa, H. Nishikage, M. Izumi, Y. Takamitsu, Association of hyperhomocysteinemia with plasma sulfate and urine sulfate excretion in patients with progressive renal disease, Am. J. Kidney Dis., 40 (2002) 909-915.

[6] E.L.C. Silveira, L.B. de Caland, M. Tubino, Simultaneous quantitative analysis of the acetate, formate, chloride, phosphate and sulfate anions in biodiesel by ion chromatography, Fuel, 124 (2014) 97-101.

[7] T.K. Ghorpade, M. Patri, S.P. Mishra, Highly sensitive colorimetric and fluorometric anion sensors based on mono and di-calix[4]pyrrole substituted diketopyrrolopyrroles, Sens. Actuat. B Chem., 225 (2016) 428-435.

[8] B. Sen, M. Mukherjee, S. Pal, S. Sen, P. Chattopadhyay, A water soluble copper(II) complex as a HSO4- ion selective turn-on fluorescent sensor applicable in living cell imaging, RSC Adv., 5 (2015) 50532-50539.

[9] J. Singh, M. Yadav, A. Singh, N. Singh, Zinc metal complex as a sensor for simultaneous detection of fluoride and HSO4- ions, Dalton Trans., 44 (2015) 12589-12597.

[10] D. Zhao, C. Chen, L. Lu, F. Yang, X. Yang, A label-free colorimetric sensor for sulfate based on the inhibition of peroxidase-like activity of cysteamine-modified gold nanoparticles, Sens. Actuat. B Chem., 215 (2015) 437-444.

[11] T. Guinovart, P. Blondeau, F.J. Andrade, Sulphate-selective optical microsensors: overcoming the hydration energy penalty, Chem. Commun., 51 (2015) 10377-10380.

[12] M. Fibbioli, M. Berger, F.P. Schmidtchen, E. Pretsch, Polymeric membrane electrodes for monohydrogen phosphate and sulfate, Anal. Chem., 72 (2000) 156-160. 
[13] P.D. Beer, J. Cadman, J.M. Lloris, R. Martinez-Manez, M.E. Padilla, T. Pardo, D.K. Smith, J. Soto, Selective electrochemical recognition of sulfate over phosphate and phosphate over sulfate using polyaza ferrocene macrocyclic receptors in aqueous solution, J. Chem. Soc. Dalton Trans., (1999) 127-133.

[14] C. Coll, R.H. Labrador, R.M. Manez, J. Soto, F. Sancenon, M.J. Segui, Ionic liquids promote selective responses towards the highly hydrophilic anion sulfate in PVC membrane ion-selective electrodes, Chem. Commun., (2005) 3033-3035.

[15] M.J. Berrocal, A. Cruz, I.H.A. Badr, L.G. Bachas, Tripodal ionophore with sulfate recognition properties for anion-selective electrodes, Anal. Chem., 72 (2000) 5295-5299.

[16] S. Firouzabadi, I. Razavipanah, R. Zhiani, M. Ghanei-Motlagh, M.R. Salavati, Sulfate-selective electrode based on a bis-thiourea ionophore, Monatsh. Chem., 144 (2013) 113-120.

[17] S. Nishizawa, P. Buhlmann, K.P. Xiao, Y. Umezawa, Application of a bis-thiourea ionophore for an anion selective electrode with a remarkable sulfate selectivity, Anal. Chim. Acta, 358 (1998) 35-44.

[18] Y. Liu, Y. Qin, D. Jiang, Squaramide-based tripodal ionophores for potentiometric sulfate-selective sensors with high selectivity, Analyst, 140 (2015) 5317-5323.

[19] R.B.P. Elmes, K.K.Y. Yuen, K.A. Jolliffe, Sulfate-selective recognition by using neutral dipeptide anion receptors in aqueous solution, Chem. Eur. J., 20 (2014) 7373-7380.

[20] R. Cui, Q. Li, D.E. Gross, X. Meng, B. Li, M. Marquez, R. Yang, J.L. Sessler, Y. Shao, Anion transfer at a microwater/1,2-dichloroethane interface facilitated by $\beta$-octafluoro-meso-octamethylcalix[4]pyrrole, J. Am. Chem. Soc., 130 (2008) 14364-14365.

[21] R.A.W. Dryfe, S.S. Hill, A.P. Davis, J.B. Joos, E.P.L. Roberts, Electrochemical quantification of high-affinity halide binding by a steroid-based receptor, Org. Biomol. Chem., 2 (2004) 2716-2718.

[22] F. Kivlehan, W.J. Mace, H.A. Moynihan, D.W.M. Arrigan, Potentiometric evaluation of calix[4]arene anion receptors in membrane electrodes: Phosphate detection, Anal. Chim. Acta, 585 (2007) 154-160.

[23] S. Nishizawa, T. Yokobori, R. Kato, K. Yoshimoto, T. Kamaishi, N. Teramae, Hydrogen-bond forming ionophore for highly efficient transport of phosphate anions across the nitrobenzene-water interface, Analyst, 128 (2003) 663-669.

[24] T. Shioya, S. Nishizawa, N. Teramae, Anion recognition at the liquid-liquid interface. Sulfate transfer across the 1,2-dichloroethane-water interface facilitated by hydrogen-bonding ionophores, J. Am. Chem. Soc., 120 (1998) 11534-11535.

[25] D. Hu, H. Wang, K. Gao, X. Jiang, M. Wang, Y. Long, Y. Chen, Anion transfer across "anion channels" at the liquid/liquid interface modified by anion-exchange membrane, RSC Adv., 4 (2014) 57035-57040.

[26] H.J. Lee, P.D. Beattie, B.J. Seddon, M.D. Osborne, H.H. Girault, Amperometric ion sensors based on laserpatterned composite polymer membranes, J. Electroanal. Chem., 440 (1997) 73-82.

[27] R. Zazpe, C. Hibert, J. O'Brien, Y.H. Lanyon, D.W.M. Arrigan, Ion-transfer voltammetry at silicon membranebased arrays of micro-liquid-liquid interfaces, Lab. Chip, 7 (2007) 1732-1737.

[28] O. Valent, J. Koryta, M. Panoch, Voltammetric study of ion transfer across the water/o-nitrophenyloctyl ether interface: Part I. Reversible process, J. Electroanal. Chem., 226 (1987) 21-25. 
[29] F. Busetti, M. Ruff, K.L. Linge, Target screening of chemicals of concern in recycled water, Environmental Science: Water Res. Technol., 1 (2015) 659-667.

[30] J. Strutwolf, M.D. Scanlon, D.W.M. Arrigan, Electrochemical ion transfer across liquid/liquid interfaces confined within solid-state micropore arrays - simulations and experiments, Analyst, 134 (2009) 148-158.

[31] Z. Samec, Electrochemistry at the interface between two immiscible electrolyte solutions, Pure Appl. Chem., 76 (2004) 2147-2180.

[32] D. Zhan, S. Mao, Q. Zhao, Z. Chen, Hu, P. Jing, M. Zhang, Z. Zhu, Y. Shao, Electrochemical investigation of dopamine at the water/1,2-dichloroethane interface, Anal. Chem., 76 (2004) 4128-4136.

[33] H. Wang, L.L. Sun, R.D. Armstrong, Measurements of diffusion coefficients of the neutral ionophores in plasticized PVC membranes using small amplitude ac/dc techniques, Electrochim. Acta, 41 (1996) 1491-1493.

[34] R.P. Buck, E. Lindner, Recommendations for nomenclature of ion-selective electrodes - (IUPAC Recommendations 1994), Pure Appl. Chem., 66 (1994) 2527-2536.

[35] M.A. Rahman, H. Doe, M. Okamoto, R. Arakawa, Voltammetric and electrospray ionization mass spectrometric studies of the facilitated ion transfer of sodium and potassium cations by naphtho-15-crown- 5 across the water | 1,2-dichloroethane interface, Electrochim. Acta, 44 (1998) 39-46.

[36] M.A. Rahman, H. Doe, N. Sakurada, R. Arakawa, Facilitated ion-transfer of alkaline-earth metal cations by naphtho-15-crown-5 across the water | 1,2-dichloroethane interface: voltammetric and electrospray ionization mass spectrometric studies, Electrochim. Acta, 47 (2001) 623-631.

[37] T.J. Stockmann, A.-M. Montgomery, Z. Ding, Correlation of stoichiometries for $\mathrm{Rb}^{+}$extraction determined by mass spectrometry and electrochemistry at liquid | liquid interfaces, Anal. Chem., 84 (2012) 6143-6149.

[38] T.J. Stockmann, J. Zhang, A.M. Montgomery, Z. Ding, Electrochemical assessment of water/ionic liquid biphasic systems towards cesium extraction from nuclear waste, Anal. Chim. Acta, 821 (2014) 41-47.

[39] T.J. Stockmann, Y. Lu, J. Zhang, H.H. Girault, Z.F. Ding, Interfacial complexation reactions of $\mathrm{Sr}^{2+}$ with octyl(phenyl)-N,N-diisobutylcarbamoylmethylphosphine oxide for understanding its extraction in reprocessing spent nuclear fuels, Chem. Eur. J., 17 (2011) 13206-13216.

[40] J.C. Kruithof, P.C. Kamp, H.C. Folmer, M.M. Nederlof, S.C.J.M. van Hoof, Development of a membrane integrity monitoring strategy for the UF/RO Heemskerk drinking water treatment plant, Water Sci. Technol., 1 (2001) 261-271.

[41] M.L. Pype, B.C. Donose, L. Marti, D. Patureau, N. Wery, W. Gernjak, Virus removal and integrity in aged RO membranes, Water Res., 90 (2016) 167-175. 


\section{SUPPLEMENTARY INFORMATION}

\section{Evaluation of interfacial sulfate complexation by a bis-thiourea ionophore at water-}

organic interfaces using microelectrochemistry and high resolution mass spectrometry

Eva Alvarez de Eulate, ${ }^{a, c}$ Francesco Busetti ${ }^{b, c}$ and Damien W. M. Arrigan ${ }^{a, c}$

${ }^{a}$ Nanochemistry Research Institute, ${ }^{b}$ Curtin Water Quality Research Centre, and 'Department of Chemistry, Curtin University, GPO Box U1987, Perth, Western Australia, 6845, Australia
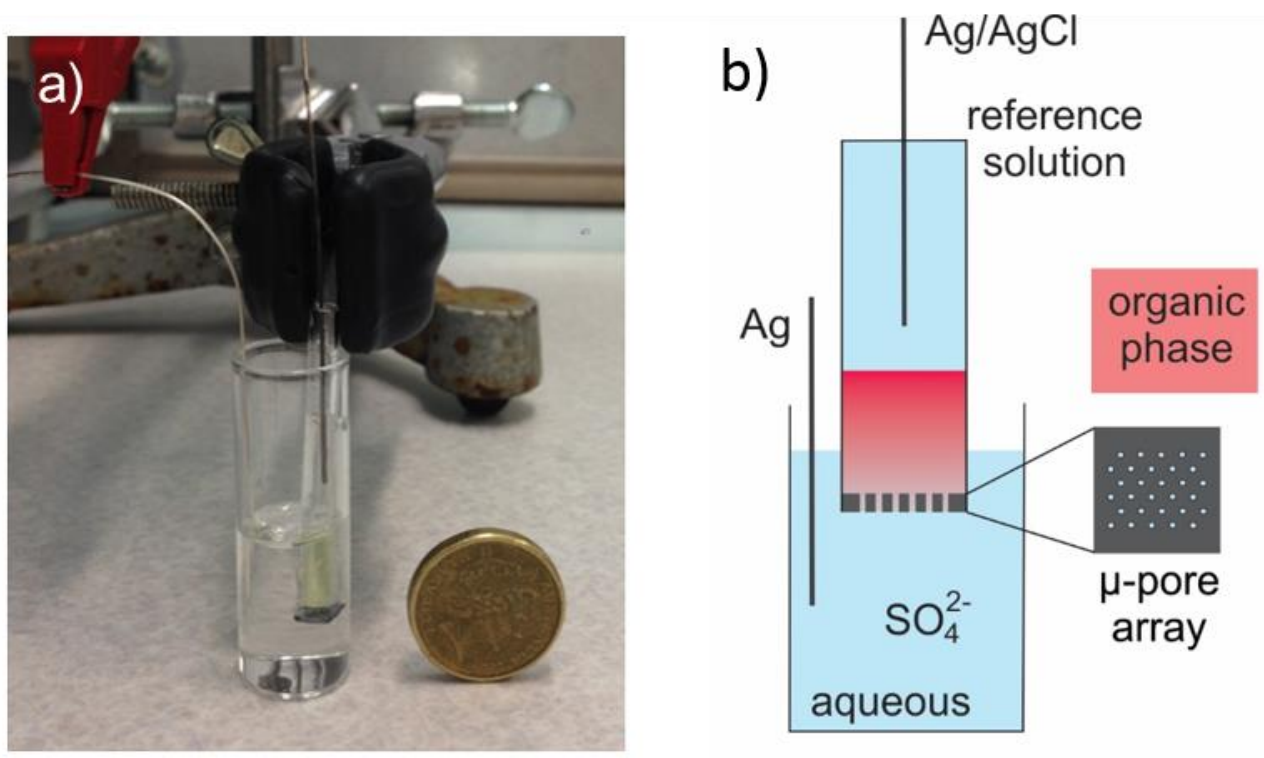

c)

$\mathrm{Ag} \mid$
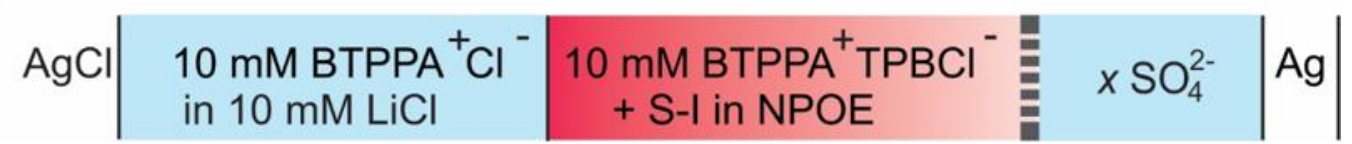

Figure SI-1. a) Photograph of the two-electrode set-up of the liquid-liquid electrochemical cell beside an Australian \$2 coin (20.5 mm diameter); b) schematic diagram of the electrochemical cell set-up showing all of the components; c) schematic of the electrochemical cell with aqueous and organic phase compositions; NPOE is the organic solvent, $\mathrm{S}-\mathrm{I}$ is the sulfate-ionophore, $\mathrm{x}$ is the sulfate $\left(\mathrm{SO}_{4}{ }^{2-}\right)$ concentration (M), BTPPATPBCl is the organic electrolyte present in the organic phase. 

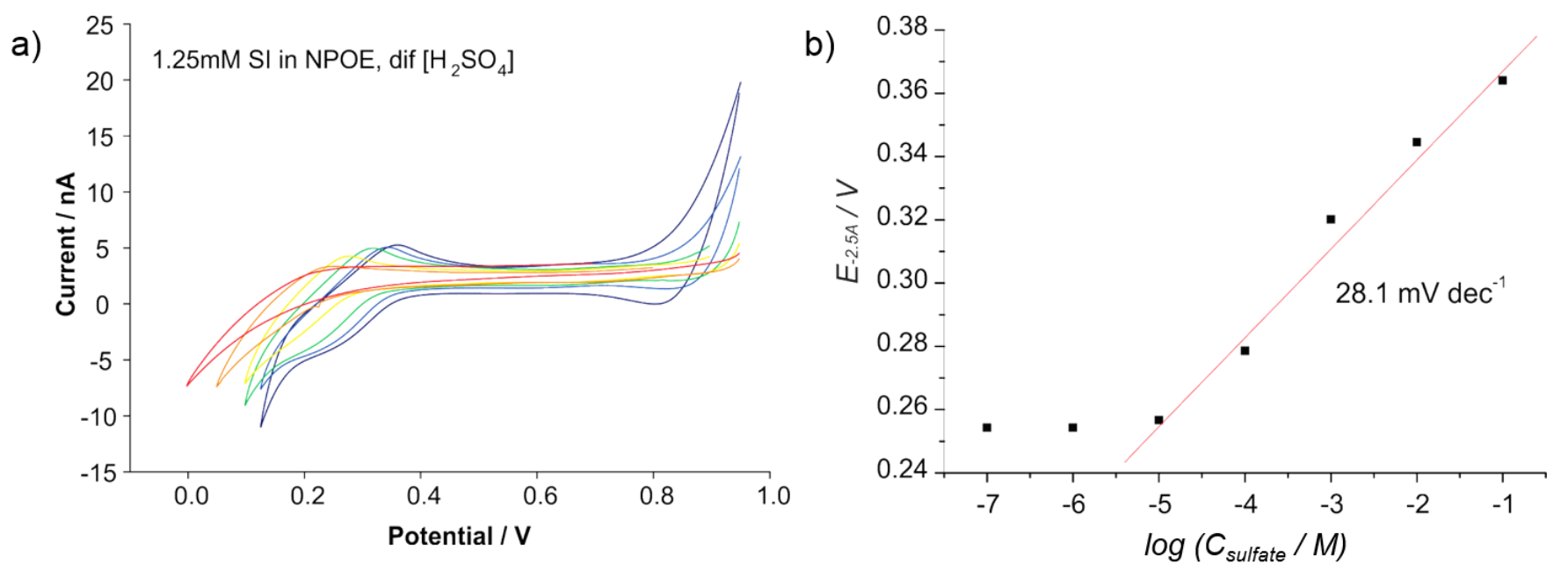

Figure SI-2. a) $\mathrm{CV}$ of different $\mathrm{H}_{2} \mathrm{SO}_{4}$ concentrations $\left(10^{-7}-10^{-1} \mathrm{M}\right)$ at W/NPOE micro-interfaces in the presence of $1.25 \times 10^{-3} \mathrm{M}$ sulfate-ionophore I in the organic phase. b) Half-wave potential measured at $i$ $=-2.5 \mathrm{nA}$ vs $\log \left(C_{\text {sulfate }} / \mathrm{M}\right)$. Here the potential is reported versus $\mathrm{Ag} / \mathrm{AgCl}$.

Table SI-1. Summary of sensitivity, regression coefficient ( $r$ ) and limit of detection (LOD) obtained from the forward and reverse voltammograms when testing different concentrations of $\mathrm{Na}_{2} \mathrm{SO}_{4}$ in the water phase. The organic phase contained: $2.5 \times 10^{-3} \mathrm{M}$ sulfate ionophore and $0.01 \mathrm{M} B T P P A T P B C l$ in NPOE.

\begin{tabular}{|c|c|c|c|c|c|}
\hline \multicolumn{3}{|c|}{ Forward peak } & \multicolumn{3}{|c|}{ Reverse peak } \\
\hline $\begin{array}{c}\text { sensitivity/ } \\
\text { mV dec }^{-1}\end{array}$ & $r$ & LOD / M (ng ml-1) & $\begin{array}{c}\text { sensitivity/ } \\
\mathrm{mV} \mathrm{dec}^{-1}\end{array}$ & $r$ & LOD / M (ng ml-1) \\
\hline 27.6 & 0.995 & $2 \times 10^{-6}(192)$ & 23.7 & 0.999 & $6 \times 10^{-7}(58)$ \\
\hline 36 & 0.966 & $7 \times 10^{-7}(67)$ & 16.5 & 0.978 & $1 \times 10^{-6}(96)$ \\
\hline 28.3 & 0.999 & $1 \times 10^{-6}(96)$ & 26.2 & 0.991 & $3 \times 10^{-7}(29)$ \\
\hline 32.6 & 0.982 & $2 \times 10^{-7}(19)$ & 22.4 & 0.988 & $1 \times 10^{-6}(96)$ \\
\hline 38 & 0.988 & $3 \times 10^{-7}(29)$ & 23.0 & 0.990 & $1 \times 10^{-5}(961)$ \\
\hline 24.1 & 0.979 & $1 \times 10^{-6}(96)$ & 24.4 & 0.991 & $2 \times 10^{-6}(192)$ \\
\hline 26.9 & 0.952 & $1 \times 10^{-6}(96)$ & 25.0 & 0.982 & $2 \times 10^{-6}(192)$ \\
\hline 27.8 & 0.972 & $2 \times 10^{-6}(192)$ & 27.8 & 0.987 & $1 \times 10^{-6}(96)$ \\
\hline 25.2 & 0.983 & $2 \times 10^{-7}(19)$ & 28.6 & 0.962 & $3 \times 10^{-7}(29)$ \\
\hline
\end{tabular}

